\title{
Solid-phase extraction of sulfonylurea herbicides from water samples with single-walled carbon nanotubes disk
}

\author{
Hongyun Niu • Yali Shi • Yaqi Cai • Fusheng Wei • \\ Guibin Jiang
}

Received: 31 January 2008 / Accepted: 10 June 2008 /Published online: 2 July 2008

(C) Springer-Verlag 2008

\begin{abstract}
This study presents a new, easily made and practical solid-phase extraction disk, a single-walled carbon nanotubes (SWCNTs) disk. The properties of the disk were evaluated by extracting large volumes of aqueous solution (500-3,000 mL) spiked with trace levels of sulfonylurea herbicides, metsulfuron-methyl, chlorsulfuron, bensulfuronmethyl, pyrazosulfuron-ethyl, and chlorimuron-ethyl. The adsorption of analytes on the SWCNTs disk was more favorable at $\mathrm{pH} 3.0$, and the adsorbed sulfonylurea herbicides could be eluted completely with acetonitrile ( $1 \%$ acetic acid) solvent. The disks were stacked to enhance their extraction ability to analytes. The triple layered SWCNTs disks system showed excellent extraction efficiency when the sample volume was up to $3,000 \mathrm{~mL}$. A comparative study was conducted with a commercial $\mathrm{C}_{18}$ disk and an activated carbon disk. The SWCNTs disks showed an adsorption capacity comparable to sulfonylurea herbicides to the $\mathrm{C}_{18}$ disk and activated carbon disk, but the analytes retained on the activated carbon disk were hardly desorbed. Finally, the triple layered SWCNTs disks system was used to pretreat $1,000 \mathrm{~mL}$ of several environmental water samples spiked with the analytes, and satisfactory recoveries (79-102\%) were obtained. Detection limits of 1.1-7.2 $\mathrm{ng} \mathrm{L}^{-1}$ for analytes were achieved under the optimized conditions.
\end{abstract}

\footnotetext{
H. Niu $\cdot$ Y. Shi $\cdot$ Y. Cai $(\bowtie) \cdot$ G. Jiang

State Key Laboratory of Environmental Chemistry and

Ecotoxicology, Research Center for Eco-Environmental Science,

Chinese Academy of Sciences,

Beijing 100085, China

e-mail: caiyaqi@rcees.ac.cn

F. Wei $(\bowtie)$

China National Environmental Monitoring Center,

Beijing 100029, China

e-mail: weifs@public3.bta.net.cn
}

Keywords Solid-phase extraction · Single-walled carbon nanotubes disk · Sulfonylurea herbicides $\cdot$ Water sample

Sulfonylureas, introduced in 1982 by the Dupont Corporation, were developed for weed control in cereal crops all around the world $[1,2]$. Because of their low application rates $\left(10-40 \mathrm{~g} \mathrm{ha}^{-1}\right)$, and unprecedented herbicidal activity, they have become very popular as replacements for old high-application-rate herbicides [1-6]. However, the polar nature and fairly high water solubility of the sulfonylurea herbicides result in their high mobility; consequently they are detected in natural waters $[4,7]$. Due to their high phytotoxicity and adverse impacts to mammals, they are regarded as potential water pollutants and presenting environmental risks, especially for crops $[8,9]$, aquatic plants and microorganisms $[10,11]$, and indirectly affect the whole trophic food web of aqueous biota, such as ponds.

The sulfonylurea residues in water samples have been extensively analyzed by LC methods using an ultraviolet (UV) detector or a diode array detector (DAD) [12-15]. Due to the fact that the UV detection often lacks the required sensitivity, a preconcentration step is required before HPLC-UV/DAD detection. Solid-phase extraction (SPE), widely accepted in environmental analysis [16], is usually selected for sample preparation to achieve adequate sensitivity for the analysis of herbicides in natural waters by HPLC $[12,17]$. SPE is available in two formats generally, cartridges and disks. Incorporating adsorbents of small particle size, the disk format possesses a larger surface area than the cartridge, resulting in good mass transfer and fast flow rates [18]. In addition, the extraction efficiency of the disk was found to be sufficient for preconcentration of herbicides in natural waters [12]. A variety of adsorbents in disk format are available for the extraction of pesticides from water samples, and $\mathrm{C}_{18}$ is one of the most widely used 
adsorbents $[18,19]$. As a new kind of potent adsorbent, carbon nanotubes (including single-walled carbon nanotubes, SWCNTs, and multi-walled carbon nanotubes, MWCNTs) have been packed into cartridges to extract trace levels of organic compounds from environmental water samples. They have shown excellent extraction ability to various compounds with different polarity such as non-polar, moderate polar and highly polar compounds [20-26]. Here we report a novel approach in which SWCNTs adsorbents are assembled into a unique disk by means of a filtration process and firmly fixed on a piece of qualitative filter. The SWCNTs filter should be used as an effective SPE disk to preconcentrate trace sulfonylurea herbicides from water samples.

The objectives of this study were to demonstrate the validity of the SWCNTs disk for pretreating water samples, and then compare the extraction efficiency of the new disk with a commercial $\mathrm{C}_{18}$ disk and an activated carbon disk for sulfonylurea herbicide. Finally, the SWCNTs disks were used to analyze the presence of these compounds in several real water samples.

\section{Experimental}

\section{Chemical and materials}

Metsulfuron-methyl, chlorsulfuron, bensulfuron-methyl, pyrazosulfuron-ethyl, and chlorimuron-ethyl at a concentration of $100 \mu \mathrm{g} \mathrm{mL}^{-1}$ were purchased from the Institute of Environmental Protection and Monitoring, Department of Agriculture (Beijing, China, http://www.aepi.org.cn). Working solutions were prepared daily by appropriate dilution of the stock solutions with water. Ultrapure water was prepared in the lab using a Milli-Q Advantage A10 reagent water system from Millipore (Milford, MA, USA, http:// www.millipore.com). HPLC-grade acetonitrile and methanol were obtained from Merck (Darmstadt, Germany, http://www. merck.com). Sodium hydroxide and hydrochloric acid were of analytical grade, and supplied by Beijing Chemicals
Corporation (Beijing, China, http://www.crc-bj.com). SWCNTs were kindly donated by Nankai University, (Tianjin, China) and the SWCNTs were observed by transmission electron microscope (TEM; JEM-2011) under an acceleration voltage of $200 \mathrm{kV}$. The average external diameters and internal diameters were in the range of 1.5-2.5 and 1.0-2 nm, respectively (Fig. 1a). The specific surface area of SWCNTs was determined by the BET method, and it was shown to be $297.72 \mathrm{~m}^{2} \mathrm{~g}^{-1}$. The qualitative filter paper (Hangzhou special paper industry Co. Ltd., HangZhou, China, http://www.special-paper.com) used to support SWCNTs adsorbent was $0.20-0.22 \mathrm{~mm}$ in thickness, and the diameter of the filter was $47 \mathrm{~mm}$. The ENVITM-18 DSK SPE disk and Empore ${ }^{\mathrm{TM}}$ activated carbon disk $(\Phi=47 \mathrm{~mm}$, $500 \mathrm{mg}$, http://www.sigmaaldlich.com) were purchased from Supelco (Bellefonte, PA, USA) and 3 M Inc. (St. Paul, MN, USA, http://www.3m.com), respectively.

\section{Chromatographic conditions}

The detection of sulfonylurea was performed by a Dionex SUMMIT ${ }^{\circledR}$ HPLC system (Dionex, USA, http://www. dionex.com) with a PDA-100 photodiode array detector. The separations were conducted on a Diamonsil ${ }^{\circledR} \mathrm{C}_{18}$ column $(250 \times 4.6 \mathrm{~mm}$; particle size, $5 \mu \mathrm{m})$ (Dikma Technologies, Beijing, China, http://dikma.gdbnet.cn). Spectrophotometric detection of analytes was performed at $236 \mathrm{~nm}$. Gradient separations for analytes were carried out using acetonitrile containing $0.5 \%$ acetic acid and acetonitrile-water (10: 90, $V / V$ ) containing $0.5 \%$ acetic acid as the $\mathrm{A}$ and $\mathrm{B}$ solvents, respectively. The linear gradient profile was $10 \%$ $\mathrm{A} / 90 \% \mathrm{~B}$ solvent maintained in the first $1.5 \mathrm{~min}$ and $37 \%$ $\mathrm{A} / 63 \% \mathrm{~B}$ solvent in the next $2.5 \mathrm{~min}$ (held for $9 \mathrm{~min}$ ), after which the mobile phase was returned to the initial conditions in $2 \mathrm{~min}$. The flow rate was $1 \mathrm{~mL} \mathrm{~min}{ }^{-1}$. A personal computer equipped with a Chromeleon program for HPLC systems was used to acquire and process chromatographic data. The peak area was used as the analytical measurement.
Fig. 1 SEM image (a) of SWCNTs and image SWCNTs disk (b)
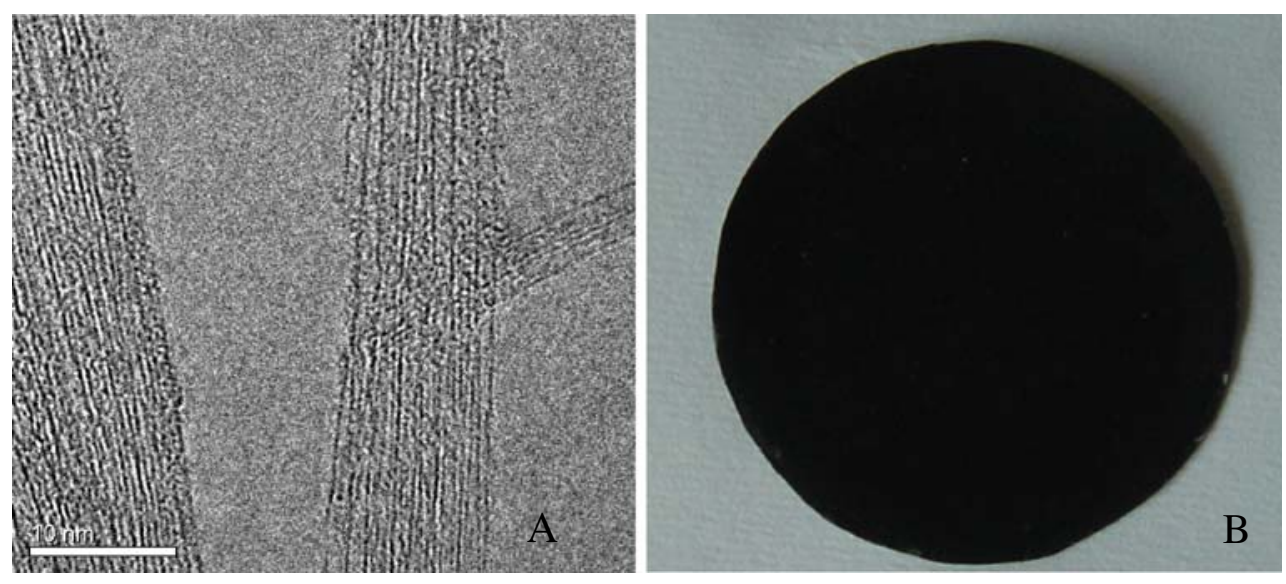
Preparation of SPE disk

To produce an SPE disk, $30 \mathrm{mg}$ of SWCNTs adsorbent were ultrasonicated in $50 \mathrm{~mL}$ solution containing $5 \%$ of sodium dodecyl sulfate (SDS) for $30 \mathrm{~min}$. After thorough dispersion of the SWCNT aggregates, the suspension was filtered through a 47-mm-diameter qualitative filter paper with a vacuum pump, thus the SWCNT adsorbents were distributed on the filter uniformly. The disk was washed with methanol and water successively to get rid of the residual SDS. The disk was allowed to dry at room temperature. The image of SWCNTs disk is shown in Fig. $1 \mathrm{~b}$.

\section{Solid-phase extraction procedure}

The purified water or water samples were extracted onto the SWCNTs disks, $\mathrm{C}_{18}$ disk or activated carbon disk using a vacuum filtration apparatus. The glass filtration apparatus was washed with methanol and water before extraction. Prior to use, the disks were conditioned with $10 \mathrm{~mL}$ of methanol and then $10 \mathrm{~mL}$ of water. Then different volumes of samples spiked with five analytes were passed through the preconditioned disks. After sample extraction, the disks were allowed to air dry under vacuum for $5 \mathrm{~min}$, then the analytes were eluted into test tubes using eluent. In this step, the eluent was rinsed down the sides of the glass filtration apparatus. One should be careful not to expose the surface of the $\mathrm{C}_{18}$ disk to air until the entire sample has been drawn through the disk during the disk conditioning and sample addition steps. The eluent was dried with a stream of nitrogen and reconstituted in $1.0 \mathrm{~mL}$ of acetonitrile. Aliquots $(50 \mu \mathrm{L})$ were injected into the HPLC system for analysis.

\section{Sampling}

A tap water sample was collected from our laboratory, and a well water sample was from the campus of China Agricultural University. River water samples were collected from Jing Mi canal and Xiaoqinghe river (Beijing). The water samples were filtered immediately through $0.22-\mu \mathrm{m}$ filters to remove suspended solids, and then stored in dark glass containers at a temperature of $4{ }^{\circ} \mathrm{C}$. Extraction of real water samples was carried out under the optimized method described earlier.

\section{Results and discussion}

\section{SWCNTs disks}

It is reported that the strong van der Waals interactions among SWCNTs lead to the highly adhesive structure with tube ends embedded in the bundles [27]. When determined by $\mathrm{BET}$, the $\mathrm{N}_{2}$ molecules hardly enter into the inner surface of the bundles [28], so the detected surface area of raw SWCNTs is significantly smaller than the theoretical BET area of 2,630 $\mathrm{m}^{2} \mathrm{~g}^{-1}$ [28]. Furthermore, the adhesive structure of the raw SWCNTs will lead to the uneven distribution of particles on the filter surface [29]. Therefore, to prepare an SPE disk, the tube ends must be released from the contorted bundles (debundling process). Both the surfactant treatment and ultrasonic process [27] can help the debundling of the particles; consequently, the bundle size will be reduced resulting in the enhancement of the SWCNTs external area. Zheng et al. [30] has proved that a sheet made of $37 \mathrm{mg}$ of SWCNTs (47 mm in diameter, and $60 \mu \mathrm{m}$ in thickness) possessed a high specific surface area of $\sim 700 \mathrm{~m}^{2} \mathrm{~g}^{-1}$. During the filtration process, the dispersed SWCNTs are distributed homogenously on the filter surface. The interactions among the nanotubes are so strong that the stress generated by nanotube sheets perpendicular to the disk surface is about five times that of a human skeletal muscle [31]. Therefore, the nanotubes can be fixed on the filter (even possessing large pore size) surface without leaking or peeling during the process of filtration or sample loading. In our study, the sheet was typically $30 \mu \mathrm{m}$ in thickness, as measured with a micrometer, and had density of $\sim 0.5 \mathrm{~g} \mathrm{~cm}^{-3}$ on the basis of the mass, area, and thickness of the sheet.

\section{Effect of solution $\mathrm{pH}$}

The selected analytes were weak acids in nature with the $\mathrm{p} K_{\mathrm{a}}$ value varying from 3.6 to 5.2 . As shown in Table 1 , the solubility of sulfonylurea herbicides in water were increased drastically with the solution $\mathrm{pH}$, and when the $\mathrm{pH}$ was up to 7.0, the solubility of metsulfuron-methyl, chlorsulfuron and chlorimuron ethyl was much higher than $1,000 \mathrm{mg} \mathrm{L}^{-1}$, indicating the high polarity of the analytes. Since the retention of sulfonylurea herbicides on the SWCNTs adsorbents was mainly based on hydrophobic interaction, adsorption of the analytes is preferable in their uncharged state. Therefore, the sample $\mathrm{pH}$ would play an important role in the enrichment of the sulfonylurea herbicides. A series of experiments were designed to investigate the influence of sample $\mathrm{pH}$ over the range of $\mathrm{pH}$ 2.5-8.5. According to the results shown in Fig. 2, the adsorption of all the analytes was more favorable in acidic solution. For metsulfuron-methyl, total recovery was achieved at $\mathrm{pH} 2.5$, which decreased to $95 \%$ at $\mathrm{pH} 3.0$, after which the recovery dropped clearly with the increase of $\mathrm{pH}$; while the abrupt decrease of the recoveries for other analytes occurred when the $\mathrm{pH}$ of solution was higher than 4.6. At $\mathrm{pH} 8.2$, hardly any of the analytes was retained by the disks. So $\mathrm{pH} 3.0$ was selected in the following experiment. 
Table 1 Solubility, dissociation constants $\left(\mathrm{p} K_{\mathrm{a}}\right)$ and octanol/water partition constants $\left(\log K_{\mathrm{OW}}\right)$ of the analytes

\begin{tabular}{|c|c|c|c|}
\hline & Solubility in water $\left(\mathrm{mg} \mathrm{L}^{-1}\right)[12,32]^{\mathrm{a}, \mathrm{b}, \mathrm{c}}$ & $\mathrm{p} K_{\mathrm{a}}[12,32]^{\mathrm{a}, \mathrm{b}, \mathrm{c}}$ & $\log K_{\mathrm{ow}}(\mathrm{pH} 7)[12]^{\mathrm{a}, \mathrm{c}}$ \\
\hline Metsulfuron-methyl & 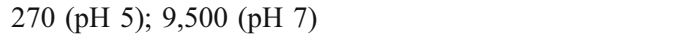 & 3.7 & -1.74 \\
\hline Chlorsulfuron & 7,000 & 3.6 & -1.34 \\
\hline Bensulfuron-methyl & 120 & 5.2 & 0.62 \\
\hline Pyrazosulfuron-ethyl & 14 & 3.7 & 1.3 \\
\hline Chlorimuron ethyl & 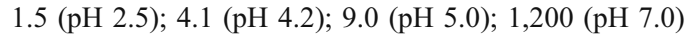 & 4.2 & 0.11 \\
\hline
\end{tabular}

${ }^{\mathrm{a}} \mathrm{http}: / /$ www.herts.ac.uk/aeru/footprint/en.htm

${ }^{\mathrm{b}} \mathrm{http}: / / \mathrm{www}$.essenagrochem.com/products.htm

${ }^{\mathrm{c}}$ http://pmep.cce.cornell.edu/profiles/herb-growthreg/cacodylic-cymoxanil.htm

\section{Effect of sample volume}

Since the breakthrough volume is an important factor for SPE to obtain reliable and reproducible analytical results, different volumes $(500-3,000 \mathrm{~mL})$ of purified water spiked with $0.5 \mathrm{ng} \mathrm{mL} \mathrm{m}^{-1}$ of each analyte were preconcentrated by different layered disk systems. The results showed that the single-layered disk system had low retention ability for most of the analytes when large volumes of sample were loaded (see Fig. 3a). The extraction ability of the disks was enhanced greatly when a double-layered disk system was used. The recoveries of all analytes remained constant until the sample volume was larger than $1,500 \mathrm{~mL}$, after which the recoveries decreased as the sample volume increased (Fig. 3b). For the triple-layered disk system, a striking retention capability for sulfonylurea herbicides was observed, and the recoveries of all the analytes were higher than $90 \%$ when the sample volume was up to $3,000 \mathrm{~mL}$ (Fig. 3c). In general, the extraction ability went up obviously with the

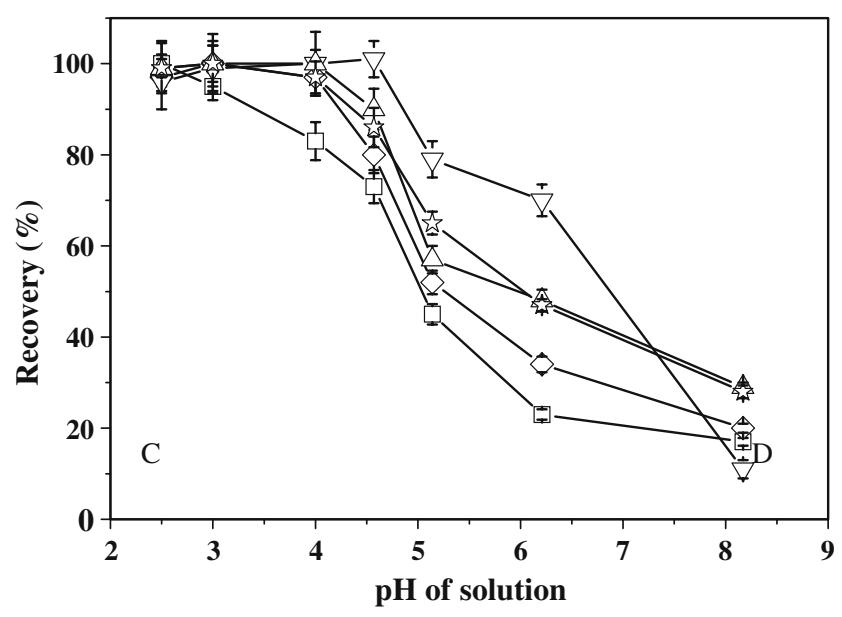

Fig. 2 Effect of solution $\mathrm{pH}$ on the recoveries of target compounds extracted with triple-layered disk system. Square, metsulfuron-methyl; diamond, chlorsulfuron; triangle, bensulfuron-methyl; inverted triangle, pyrazosulfuron-ethyl; star, chlorimuron-ethyl. Solution volume, $1,000 \mathrm{~mL}$; concentration of each analyte, $0.5 \mathrm{ng} \mathrm{mL}^{-1}$ increase in the number of disks. However, for bensulfuronmethyl and chlorimuron-ethyl, the double-layered disk system showed the same high enrichment efficiency as the triple-layered disks system.

\section{Effect of flow rate}

Flow rate was another important factor that influenced the enrichment efficiency and controlled the extraction time. The sample flow rate could be adjusted by the manifold vacuum pressure. For the single-layered disk system, the maximum flow rate of $150 \mathrm{~mL} \mathrm{~min}{ }^{-1}$ could be achieved without decreasing the retention of the analytes. As to the double-layered or triple-layered disk system, the maximum

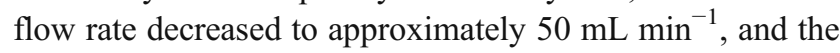
recoveries of all the analytes remained constant as the sample loading rate was varied in the range of $10-50 \mathrm{~mL}$ $\min ^{-1}$. Actually, the maximal flow rate of the triple-layered disk system was comparable to the flow rates of $\mathrm{C}_{18}$ and activated carbon disks achieved with our vacuum pump.

\section{Comparison study}

The extraction ability of SWCNTs disks to sulfonylurea herbicides was compared with a commercial $\mathrm{C}_{18}$ disk and activated carbon disk ( $\Phi=47 \mathrm{~mm}, 500 \mathrm{mg}$ ). The adsorbed analytes on SWCNTs disks and a $\mathrm{C}_{18}$ disk could be completely desorbed with acetonitrile containing percent acetic acid. However, 90\% of trapped herbicides could not be eluted from the activated carbon disk by acetonitrile, methanol, acetone, tetrahydrofuran or methylene chloride. After extraction by activated carbon disk, the percolate of different volumes was collected and preconcentrated with the $\mathrm{C}_{18}$ disk, respectively. None of the analytes was detected in the percolate, indicating that there was an irreversible interaction existing between sulfonylurea analytes and activated carbon adsorbents. Therefore, regardless of the high adsorption ability of activated carbon to sulfonylurea compounds, it could not be utilized to pretreat environmental water samples for the detection of sulfonylurea herbicide. 
A

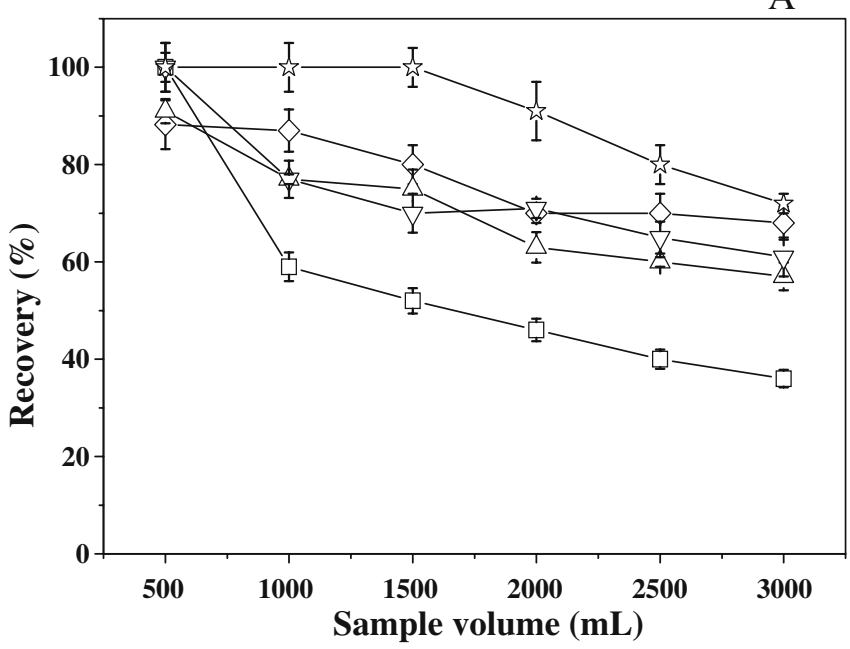

$\mathrm{C}$

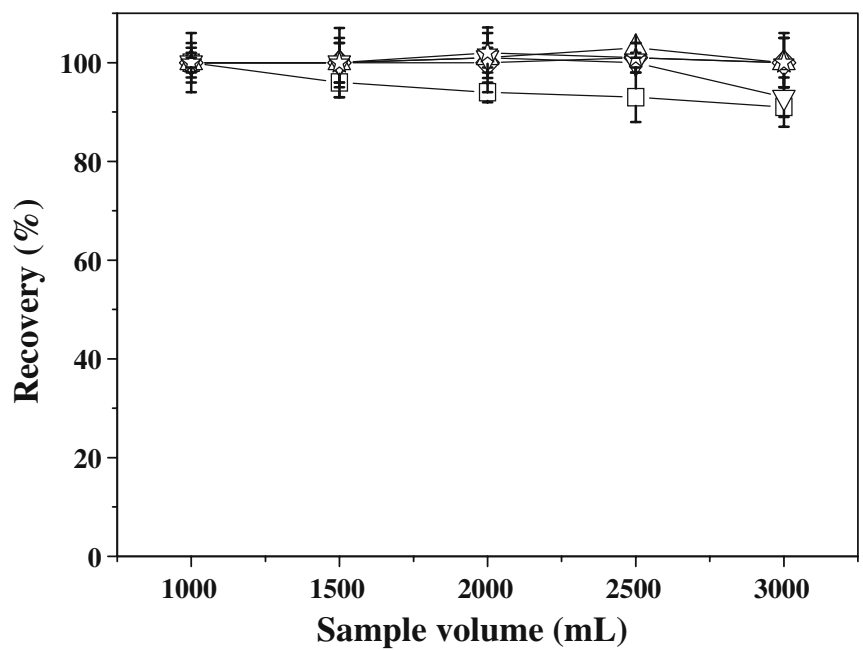

Fig. 3 Effect of sample volumes on the recoveries of analytes preconcentrated by different layered SWCNTs disk systems and an ENVITM-18 DSK $\mathrm{C}_{18}$ disk. a Single-layered disks; b double-layered disks; c triple-layered disks; $\mathbf{d ~ C}_{18}$ disk. Square, metsulfuron-methyl;

The comparison of SWCNTs disks and $\mathrm{C}_{18}$ disk is shown in Fig. 3. Similar to the triple-layered disk system, the $\mathrm{C}_{18}$ disk displayed excellent retention ability to most of the analytes when the sample volume was up to $3,000 \mathrm{~mL}$. For bensulfuron-methyl and chlorimuron-ethyl, the extraction ability of double-layered disks was even comparable with

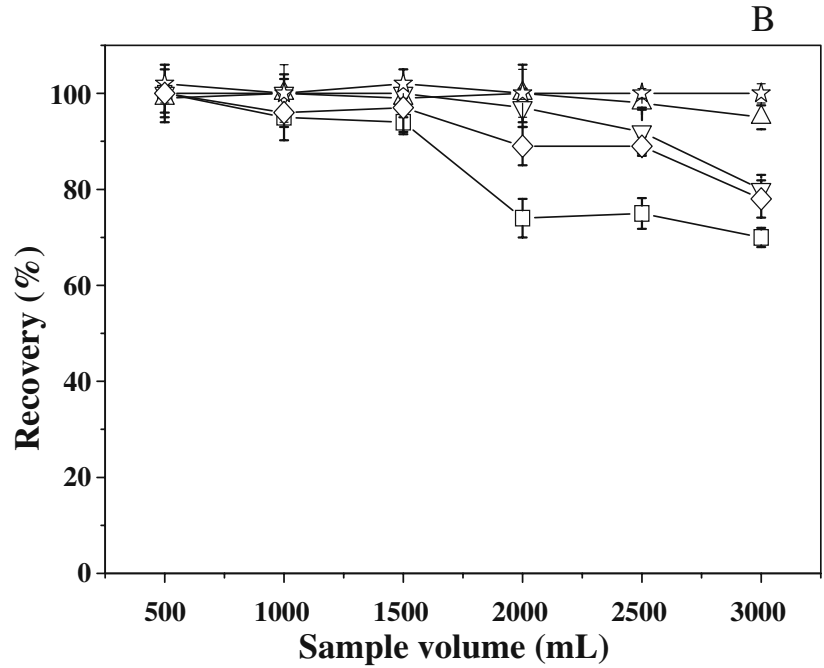

$\mathrm{D}$

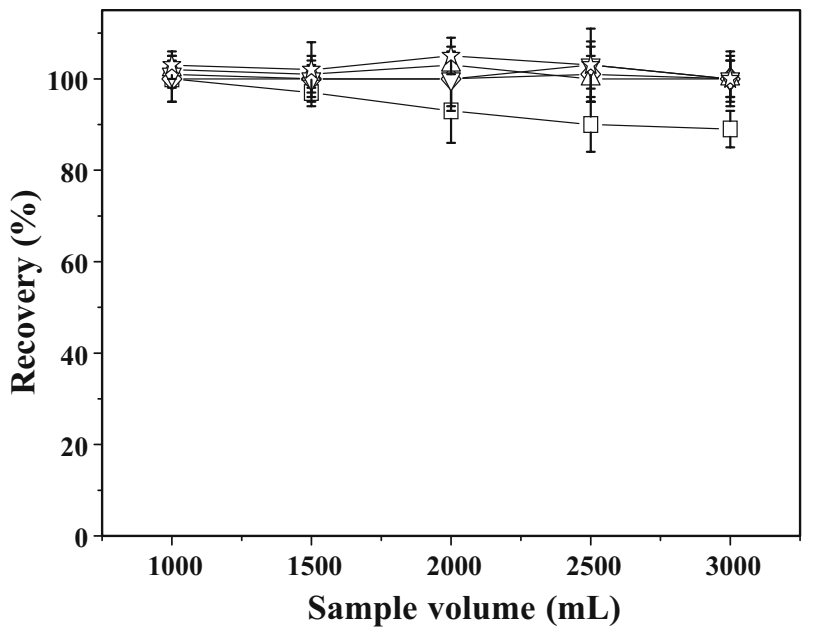

diamond, chlorsulfuron; triangle, bensulfuron-methyl; inverted triangle, pyrazosulfuron-ethyl; star, chlorimuron-ethyl. Concentration of each analyte, $0.5 \mathrm{ng} \mathrm{mL}^{-1}$

the $\mathrm{C}_{18}$ disk. It should be mentioned that the amount of SWCNTs adsorbent in each disk was only $30 \mathrm{mg}$, which was far less than the amount of $\mathrm{C}_{18}$ adsorbent $(500 \mathrm{mg})$ in one disk. Compared with the work by Zhou et al. [13], the extraction ability of the triple-layered disk system was comparable or superior to the MWCNTs cartridge (100 mg

Table 2 Analytical parameters of the HPLC-DAD method after SPE with triple-layered SWCNTs disk system

\begin{tabular}{lcccc}
\hline & Linear range $\left(\mathrm{ng} \mathrm{L}^{-1}\right)$ & Calibration equations & $R^{2}$ & Detection limit $\left(\mathrm{ng} \mathrm{L}^{-1}\right),(S / N=3)$ \\
\hline Metsulfuron-methyl & $30-3,000$ & $y=0.0015 x+0.0228$ & 0.9975 & 6.2 \\
Chlorsulfuron & $30-3,000$ & $y=0.0017 x+0.0134$ & 0.9995 & 1.1 \\
Bensulfuron-methyl & $30-3,000$ & $y=0.0013 x+0.0627$ & 0.9969 & 6.5 \\
Pyrazosulfuron-ethyl & $30-3,000$ & $y=0.0015 x-0.0224$ & 0.9998 & 2.8 \\
Chlorimuron-ethyl & $30-3,000$ & $y=0.001 x+0.0096$ & 0.9979 & 7.2 \\
\hline
\end{tabular}


Table 3 Recoveries (percent) \pm standard deviation (based on three replicates) of real water samples spiked with $200 \mathrm{ng} \mathrm{L}^{-1}$ of each target analyte

\begin{tabular}{lrrrr}
\hline & Well water & Tap water & Jing Mi canal & Xiaoqinghe River \\
\hline Metsulfuron-methyl & $99 \pm 2$ & $102 \pm 2$ & $93 \pm 1$ & $79 \pm 1$ \\
Chlorsulfuron & $99 \pm 2$ & $99 \pm 1$ & $97 \pm 3$ & $84 \pm 3$ \\
Bensulfuron-methyl & $102 \pm 2$ & $96 \pm 5$ & $95 \pm 4$ & $76 \pm 3$ \\
Pyrazosulfuron-ethyl & $99 \pm 3$ & $101 \pm 3$ & $101 \pm 1$ & $85 \pm 4$ \\
Chlorimuron-ethyl & $95 \pm 2$ & $101 \pm 1$ & $99 \pm 3$ & $91 \pm 4$ \\
\hline
\end{tabular}

Triple-layered disk system

adsorbent). So the satisfactory recoveries of the polar analytes on layered disks demonstrated the outstanding extraction capability of SWCNTs disks.

Analytical performance and sample analyses

In this experiment, a triple-layered disk system was used to preconcentrate $1,000 \mathrm{~mL}$ of water samples. Samples were acidified to $\mathrm{pH} 3$ with dilute hydrochloric acid. Under the optimal conditions, some important parameters of the proposed method, such as linear range, correlation coefficient and detection limits, were investigated. The results are listed in Table 2. It could be seen that there was an excellent linear correlation between the peak area and concentration from 30 to $3,000 \mathrm{ng} \mathrm{L}^{-1}$ for all the analytes. The detection limits of the sulfonylurea herbicides were obtained based on the signal as three-fold the baseline noise $(S / N=3)$ for extraction of $1,000 \mathrm{~mL}$ water samples. The results showed that the detection limits for all the analytes were less than $10 \mathrm{ng} \mathrm{\textrm {L } ^ { - 1 }}$. The LOD for chlortoluron was lower than that obtained by extracting from $1,000 \mathrm{~mL}$ of purified water sample with $\mathrm{C}_{18}$ Empore disk (determined by DAD-HPLC) [15] or by SPE with an Oasis HLB cartridge from $500 \mathrm{~mL}$ pure water samples [4]. Strikingly low LODs of sulfonylurea herbicides were also reported by Zhu et al. [5] (less than $10 \mathrm{ng} \mathrm{L}^{-1}$, SPE by a molecularly imprinted polymer cartridge from 1,000 mL of tap water) and Corcia et al. [14] (less than $2 \mathrm{ng} \mathrm{L}^{-1}$, achieved with a graphitized carbon blacks cartridge pretreating from $4,000 \mathrm{~mL}$ of drinking water samples), the LODs of sulfonylurea herbicides in our study were equivalent to these reports.

The proposed method had been applied to the analysis of several environmental water samples. None of the analytes were detected in these samples. To evaluate the accuracy of the proposed method, 1,000 $\mathrm{mL}$ of environmental water samples spiked with the mixture of analytes at $200 \mathrm{ng} \mathrm{L}^{-1}$ were preconcentrated. Table 3 shows the mean recoveries and standard deviations of herbicides spiked to different water samples. The recoveries obtained from well water, tap water and Jing Mi canal samples were almost 100\%. However, a matrix effect was observed on the extraction of sulfonylurea from Xiaoqinghe river water sample. It has been reported that the low $\mathrm{pH}$ of the water sample may increase the retention of humic and fulvic acids [11], therefore the extraction efficiency of SWCNTs disks was influenced when samples with more complex matrices were pretreated. The chromatograms of the Xiaoqinghe river sample and its spiked solution are shown in Fig. 4.
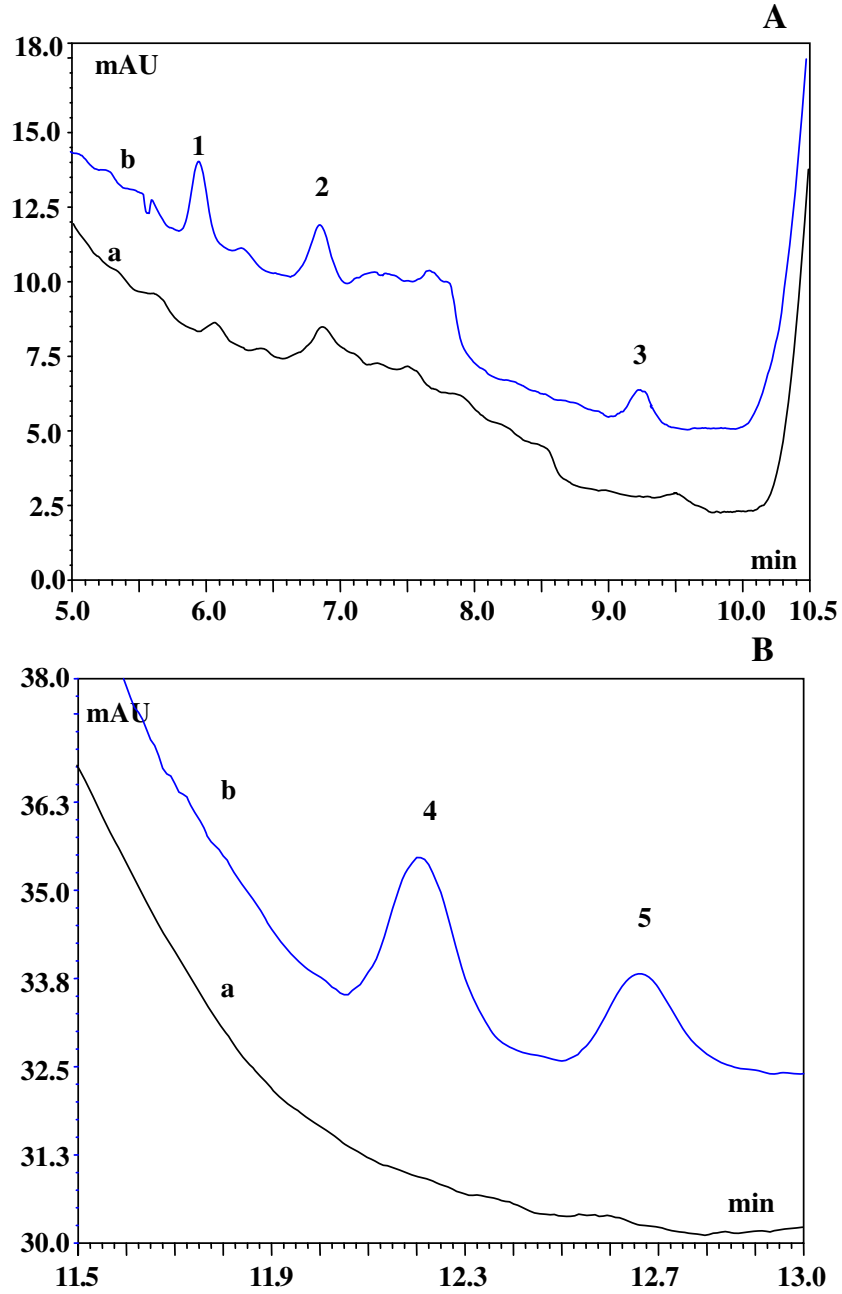

Fig. 4 a-b LC-DAD chromatograms of Xiaoqinghe river samples preconcentrated by triple-layered SWCNTs disks. (a) Xiaoqinghe river sample, (b) Xiaoqinghe river sample spiked with $0.20 \mathrm{ng} \mathrm{mL}^{-1}$ of each compound. 1, metsulfuron-methyl; 2, chlorsulfuron; 3, bensulfuronmethyl; 4, pyrazosulfuron-ethyl; 5 , chlorimuron-ethyl. Volume of water samples, $1,000 \mathrm{~mL}$; volume of eluent, acetonitrile containing $1 \%$ acetic acid, $10 \mathrm{~mL}$ 


\section{Conclusion}

A new kind of solid-phase extraction disk (SWCNTs disk) has been invented in our laboratory. The process of preparing a disk is rather simple. A comparison study showed that the SWCNTs disks exhibited similar extraction ability for sulfonylurea herbicides as an activated carbon disk and $\mathrm{C}_{18}$ disk; but unlike the activated carbon disk, the analytes adsorbed on SWCNTs disks could be desorbed easily with acetonitrile (1\% acetic acid). Due to the reasonable thickness, the disks could be stacked to treat samples together without leaking. It could be concluded that excellent recoveries would be achieved for different analytes by using different layered SWCNTs disk systems according to the hydrophobicity of the analytes. In summary, the proposed new solid-phase extraction disk showed great analytical potential for SPE of large volumes of real water samples.

Acknowledgement This work was jointly supported by the National Natural Science Foundation of China $(20475060,20621703)$ and the Major Research Program of the Chinese Academy of Sciences (KZCX2-YW-420-1)

\section{References}

1. Baker SE, Olsson AO, Needham LL, Barr DB (2005) Highperformance liquid chromatography-tandem mass spectrometry method for quantifying sulfonylurea herbicides in human urine: reconsidering the validation process. Anal Bioanal Chem 383:963

2. Degelmann P, Egger S, Jürling H, Müller J, Niessner R, Knopp D (2006) Determination of sulfonylurea herbicides in water and food samples using sol-gel glass-based immunoaffinity extraction and liquid chromatography-ultraviolet/diode array detection or liquid chromatography-tandem mass spectrometry. J Agric Food Chem 54:2003

3. Ayano E, Kanazawa H, Ando M, Nishimura T (2004) Determination and quantitation of sulfonylurea and urea herbicides in water samples using liquid chromatography with electrospray ionization mass spectrometric detection. Anal Chim Acta 507:211

4. Carabias-Martínez R, Rodríguez-Gonzalo E, Herrero-Hernández E, Hernández-Méndez J (2004) Simultaneous determination of phenyl- and sulfonylurea herbicides in water by solid-phase extraction and liquid chromatography with UV diode array or mass spectrometric detection. Anal Chim Acta 517:71

5. Zhu QZ, Degelmann P, Niessner R, Knopp D (2002) Selective trace analysis of sulfonylurea herbicides in water and soil samples based on solid-phase extraction using a molecularly imprinted polymer. Environ Sci Technol 36:5411

6. Rodriguez M, Orescan DB (1998) Confirmation and quantitation of selected sulfonylurea, imidazolinone, and sulfonamide herbicides in surface water using electrospray LC/MS. Anal Chem 70:2710

7. Perreau F, Bados P, Kerhoas L, Nélieu S, Einhorn J (2007) Trace analysis of sulfonylurea herbicides and their metabolites in water using a combination of off-line or on-line solid-phase extraction and liquid chromatography-tandem mass spectrometry. Anal Bioanal Chem 388:1265

8. Battaglin WA, Furlong ET, Burkhardt MR, Peter CJ (2000) Occurrence of sulfonylurea, sulfonamide, imidazolinone, and other herbicides in rivers, reservoirs and ground water in the Midwestern United States, 1998. Sci Tot Environ 248:123

9. Fletcher JS, Pfleeger TG, Ratsch HC (1993) Potential environmental risks associated with the new sulfonylurea herbicides. Environ Sci Technol 27:2250

10. Seguin F, Leboulanger C, Rimet F, Druart JC, Bérard A (2001) Effects of atrazine and nicosulfuron on phytoplankton in systems of increasing complexity. Arch Environ Contam Toxicol 40:198

11. Nyström B, Björnsäter B, Blanck H (1999) Effects of sulfonylurea herbicides on non-target aquatic micro-organisms: growth inhibition of micro-algae and short-term inhibition of adenine and thymidine incorporation in periphyton communities. Aquat Toxicol 47:9

12. Tran ATK, Hyne RV, Doble P (2007) Determination of commonly used polar herbicides in agricultural drainage waters in Australia by HPLC. Chemosphere 67:944

13. Zhou QX, Wang WD, Xiao JP (2006) Preconcentration and determination of nicosulfuron, thifensulfuron-methyl and metsulfuron-methyl in water samples using carbon nanotubes packed cartridge in combination with high performance liquid chromatography. Anal Chim Acta 559:200

14. Corcia AD, Crescenzi C, Samperi R, Scappaticcio L (1997) Trace analysis of sulfonylurea herbicides in water: extraction and purification by a carbograph 4 cartridge, followed by liquid chromatography with UV detection, and confirmatory analysis by an electrospray/mass detector. Anal Chem 69:2819

15. Ruberu SR, Draper WM, Perera SK (2000) Multiresidue HPLC methods for phenyl urea herbicides in water. J Agric Food Chem 48:4109

16. Carabias-Martínez R, Rodríguez-Gonzalo E, Fernández-Laespada ME, Sánchez-San Román FJ (2000) Evaluation of surface- and ground-water pollution due to herbicides in agricultural areas of Zamora and Salamanca (Spain). J Chromatogr A 869:471

17. Bruzzoniti MC, Sarzanini C, Mentasti E (2000) Preconcentration of contaminants in water analysis. J Chromatogr A 902:289

18. Thurman EM, Snavely K (2000) Advances in solid-phase extraction disks for environmental chemistry. Trend Anal Chem 19:18

19. Riley MB, Dumas JA, Gbur EE, Massey JH, Mattice JD, Mersie W, Mueller TC, Potter T, Senseman SA, Watson E (2005) Pesticide extraction efficiency of two solid phase disk types after shipping. J Agric Food Chem 53:5079

20. Cai YQ, Jiang GB, Liu JF, Zhou QX (2003) Multiwalled carbon nanotubes as a solid-phase extraction adsorbent for the determination of bisphenol A, 4- $n$-nonylphenol, and 4-tert-octylphenol. Anal Chem 75:2517

21. Suárez B, Simonet BM, Cárdenas S, Valcárcel M (2007) Determination of non-steroidal anti-inflammatory drugs in urine by combining an immobilized carboxylated carbon nanotubes minicolumn for solid-phase extraction with capillary electrophoresismass spectrometry. J Chromatogr A 1159:203

22. Cai YQ, Cai YE, Mou SF, Lu YQ (2005) Multi-walled carbon nanotubes as a solid-phase extraction adsorbent for the determination of chlorophenols in environmental water samples. J Chromatogr A 1081:245

23. Zhou QX, Ding YJ, Xiao JP (2007) Simultaneous determination of cyanazine, chlorotoluron and chlorbenzuron in environmental water samples with SPE multiwalled carbon nanotubes and LC. Chromatographia 65:25

24. Zhou QX, Xiao JP, Wang WD, Liu GG, Shi QZ, Wang JH (2006) Determination of atrazine and simazine in environmental water samples using multiwalled carbon nanotubes as the adsorbents for perconcentration prior to high performance liquid chromatography with diode array detector. Talanta 28:1309

25. Biesaga M, Pyrzynska K (2006) The evaluation of carbon nanotubes as a sorbent for dicamba herbicide. J Sep Sci 29:2241 
26. Niu HY, Cai YQ, Shi YL, Wei FS, Liu JM, Mou SF, Jiang GB (2007) Evaluation of carbon nanotubes as a solid-phase extraction adsorbent for the extraction of cephalosporins antibiotics, sulfonamides and phenolic compounds from aqueous solution. Anal Chim Acta 594:81

27. Vodenitcharova T, Mylvaganam K, Zhang LC (2007) Mechanical interaction between single-walled carbon nanotubes during the formation of a bundle. J Mater Sci 42:4935

28. Shiraishi S, Kurihara H, Okabe K, Hulicova D, Oya A (2002) Electric double layer capacitance of highly pure single-walled carbon nanotubes (HiPcoä Buckytubesä) in propylene carbonate electrolytes. Electrochem Commum 4:593

29. Vohrer U, Kolaric I, Haque MH, Roth S, Detlaff-Weglikowska U (2004) Carbon nanotube sheets for the use as artificial muscles. Carbon 42:1159
30. Zheng F, Baldwin DL, Fifield LS, Anheier NC, Aardahl CL, Grate JW (2006) Single-walled carbon nanotube paper as a sorbent for organic vapor preconcentration. Anal Chem 78:2442

31. Spinks GM, Wallace GG, Fifield LS, Dalton LR, Mazzoldi A, Rossi DD, Khayrullin II, Baughman RH (2002) Pneumatic carbon nanotube actuators. Adv Mater 14:1728

32. Smith AE (1986) Persistence of the herbicides ${ }^{14} \mathrm{C}$ chlorsulfuron and ${ }^{14} \mathrm{C}$ metsulfuron methyl in prairie soils under laboratory conditions. Bull Environ Contam Toxicol 37:698

33. Carabias-Martínez R, Rodríguez-Gonzalo E, FernándezLaespada ME, Sánchez-San Román FJ, Prado-Flores MG (2002) Determination of herbicides and metabolites by solidphase extraction and liquid chromatography: evaluation of pollution due to herbicides in surface and groundwaters. J Chromatogr A 950:157 